\title{
The effect of scapular dyskinesia on the scapular balance angle and upper extremity sensorimotor function in stroke patients with spasticity
}

\author{
Lama Saad El-Din Mahmoud $^{1 *}$ (i) and Sobhy Mahmoud Aly²
}

\begin{abstract}
Background: Post-stroke scapular dyskinesia is a predisposing factor for the affection of motor and somatosensory functions of the hemiparetic upper extremity.

Objective: The purpose of the study was to investigate the effect of scapular dyskinesia on the scapular balance angle and upper extremity sensorimotor function in stroke patients with spasticity.

Subjects and methods: Sixty patients with spasticity post-stroke participated in this study. The patients were assigned to one of the two groups as determined by the lateral scapular slide test (LSST) using the palpation meter (PALM); group A with scapular dyskinesia and group B stroke patients without scapular dyskinesia. The scapular position was determined by a measurement of scapular balance angle (SBA), and the upper extremity sensorimotor function was evaluated using Fugl-Meyer Assessment upper extremity (FMAUE) scale. The scapular balance angle and Fugl-Meyer upper extremity scores were compared between groups.

Results: There was a significant increase in the scapular balance angle of group A compared with that of group B $(p<0.001)$. Also, there was a significant decrease in sensory and motor functions of group A as measured by FuglMeyer upper extremity compared with that of group B $(p<0.001)$.

Conclusion: Scapular dyskinesia had a significant effect on the scapular balance angle and upper extremity sensorimotor function in stroke patients with spasticity. Management of scapular dyskinesia should be emphasized in the rehabilitation program for stroke patients with spasticity.
\end{abstract}

Keywords: Scapular dyskinesia, Scapular balance angle, Sensorimotor function, Stroke

\section{Background}

Upper limb incapacity considered a significant issue in stroke patients [1]. Following a stroke, there is a lowtone flaccid stage while there is no voluntary control,

\footnotetext{
* Correspondence: lamaelsedawyy@hotmail.com;

lama.elsedawy.pt@o6u.edu.eg

'Department of Neuromuscular Disorders and Its Surgery, Faculty of Physical

Therapy, October 6 University, Giza, Egypt

Full list of author information is available at the end of the article
}

trailed by spastic stage. The spastic and flaccid stages cause serious brokenness in the shoulder joint and likewise scapulothoracic joint asymmetry (dyskinesia) [2]. In the first flabby flaccid stage, there are great changes of the glenoid fossa angle because of the hypotonia of the trapezius, serratus anterior, and rhomboid muscles that reason scapular descending revolution, depression, and protraction, which may prompts, hence adding to subluxation [3]; while during the spastic stage, the tone of the flexor is the predominant in the upper extremity

\section{Springer Open}

(c) The Author(s). 2020 Open Access This article is licensed under a Creative Commons Attribution 4.0 International License, which permits use, sharing, adaptation, distribution and reproduction in any medium or format, as long as you give appropriate credit to the original author(s) and the source, provide a link to the Creative Commons licence, and indicate if changes were made. The images or other third party material in this article are included in the article's Creative Commons licence, unless indicated otherwise in a credit line to the material. If material is not included in the article's Creative Commons licence and your intended use is not permitted by statutory regulation or exceeds the permitted use, you will need to obtain permission directly from the copyright holder. To view a copy of this licence, visit http://creativecommons.org/licenses/by/4.0/. 
(UE), causing scapular withdrawal in retraction and depression with adduction at the shoulder $[4,5]$.

Changes in the position and movement of the scapula refer to the term scapular dyskinesis [6]. "Dys" alluded to "alternation of" while "kinesis" alludes to "movement" that demonstrates the loss of ordinary control of scapular movement. There are many neurological component especially joint sense and motor functions which affect developments of scapular dyskinesis [7]. In scapular dyskinesia, there might be dysrhythmia (hyper or hypo movement during elevation and bringing down of scapula) or winging (noticeable quality of any part of the medial edge or inferior angle away from the thorax) [8].

Kibler et al. [6] arranged scapular asymmetry (dyskinesia) as follows: the first type presents inferior dysfunction, because the scapular front tilting and the inferior angle are prominent, while the second type gives the medial dyskinesis with the medial border of scapula more prominent as the consequence of scapular inner pivot and the third type is the superior dysfunction with the expanded rise of the scapula during upper limb elevation. In the lateral scapular slide test, the first and second types are more evident in the position of hands-on-hips.

Shoulder dysfunction and pain in stroke is caused primarily by the irregular position of the scapulothoracic joints [9]. The draw of serratus anterior and lower trapezius guarantees a stable scapulothoracic joint that is important to diminish the hazard for subacromial impingement, most likely by giving satisfactory scapular horizontal turn and back tilting [10]. In a stroke, there is the debilitation of selective muscle performance [11]. Loss of motion or paralysis of any of these muscles brings about the winging of the medial scapula as it lifts off the thoracic divider. Also because of unopposed muscle withdrawal of the other working scapular muscles, the scapula may tilt medially or horizontally along the back thoracic divider [12].

As the upper extremity tasks happen with the consequence of the incorporated, multisegmented, successive joint movement, and muscle activation framework through the motor kinetic chain [13], scapular dyskinesia directly affects the upper limb performance.

Along these lines, the purpose of this study was to explore the impact of scapular dyskinesia on the scapula balance angle and the upper limb sensorimotor capacity in stroke persistent with spasticity. This study relies upon the appraisal of scapular balance angle (SBA) to survey the position and pivot of the scapula in clinical practice [14], and Fugl-Meyer Assessment (FMA) for estimating sensorimotor capacities for stroke patients, in light of Twitchell and Brunnstrom's idea of consecutive phases of motor return in the hemiplegic stroke patient, that is created as the main quantitative evaluative instrument [15].

\section{Methods}

The study aimed to investigate the effect of scapular dyskinesia on the scapular balance angle and upper extremity sensorimotor function in a stroke patient with spasticity.

\section{Design}

An analytic cross-sectional study was directed to investigate the impact of scapular dyskinesia on the SBA and upper extremity sensorimotor function in stroke patients with spasticity. Each evaluation was performed by the same examiner for all patients.

\section{Participants}

Sixty spastic stroke patients participated in this study. This study was conducted in the outpatient clinic of the Faculty of Physical Therapy, Neurological Department, Cairo University, and outpatient clinic of the Faculty of Physical Therapy, 6th October University Hospital. All the patients were classified by lateral scapular slide test (LSST) to group A with scapular dyskinesia and group B without scapular dyskinesia. All the patients were evaluated with a neurological examination. All the patients received verbal and written information about the study and gave written consent to participate, before the beginning of the study; Fig. 1 showed the flowchart of participants. The anonymity and confidentiality were assured, and all the procedures were performed in compliance with relevant laws and institutional guidelines.

\section{Ethics approval of the study}

The study was approved by the Institutional Ethics Committee of the Faculty of Physical Therapy, Cairo University, Egypt (No: P.T.REC/012/002400) and followed the Helsinki Declaration of 1975, as revised in 2000 for procedures involving human participants, and with a Trial registration: ClinicalTrials.gov Identifier: NCT04004949.

\section{Inclusion and exclusion criteria}

Inclusion criteria were as follows: (i) all the selected patients were analyzed and referred from a neurologist as having a stroke with onset at least 5 months, (ii) the upper extremity spasticity was ranging from grades I to III according to Modified Ashworth Scale [16], (iii) upper limb recovery stages III and IV according to Brunnstrom, and (iv) all patients body mass index (BMI) ranged from 20 to $30 \mathrm{~kg} / \mathrm{m}^{2}$ [17], with the age ranged from 45 to 60 years. Exclusion criteria were as follows: (i) difficulty to communicate or to understand test instructions, (ii) other conditions that caused upper extremity pain (for example supraspinatus or bicep tendinitis, frozen shoulder, fibromyalgia, and arthritis), (iii) complete motor disability of the upper extremity, and (iv) severe depression or other post-stroke 


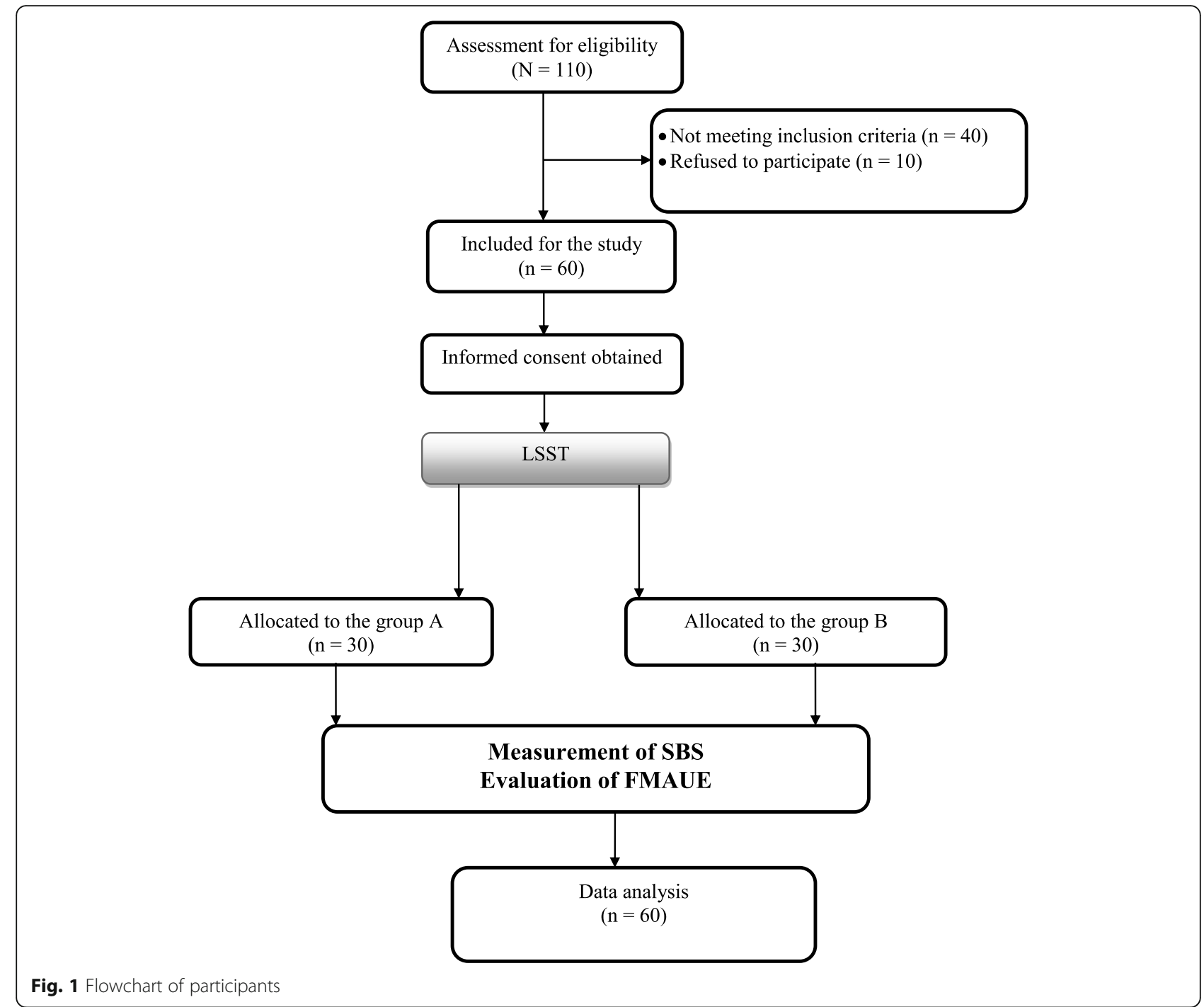

psychiatric symptoms (pathologic crying, pathologic laughter, apathy, and isolated fatigue).

\section{Sample size}

Sample size calculation was performed prior to the study using G*POWER statistical software (version 3.1.9.2; Franz Faul et al. [18], Universitat Kiel, Germany) and revealed that the minimum required size of each group was 26 . The primary outcome measure is SBA. The calculations were made using $\alpha=0.05, \beta=0.2$, and large effect size $=$ 0.8 and allocation ratio $\mathrm{N} 2 / \mathrm{N} 1=1$. The large effect size was used as it yielded a realistic sample size.

\section{Procedures}

\section{Evaluation of scapular dyskinesia}

The horizontal distance of the scapular from the thoracic spine was measured using the palpation meter (PALM) (Performance Attainment Associate, St. Paul, MN, USA).
The lateral scapular slide test (LSST) was utilized to assess the scapular dyskinesia. LSST included three static positions performed bilaterally: at $0^{\circ}$ (with the arms adducted), $45^{\circ}$ (with hands-on-hips), and $90^{\circ}$ (abduction with the arms raised in inward rotation). The patient testing position was sitting with his hip and knee in loose situated at $90^{\circ}$ of flexion and with uncovered shoulders, on a seat with a short back.

The shoulder moved in abduction actively or passively with therapist assistance. One tip of the PALM was put on one of the marked inferior angles of the scapula, and the other tip was moved to reach the marked corresponding spinous process and then the reading was taken, and this step was repeated three times for the every three previous positions, to be confirmed. The same steps were performed on the other side. Both sides' readings were recorded, and the differences between them were calculated in each position. The bilateral difference of $1.5 \mathrm{~cm}$ considered the limit for choosing 
whether scapular asymmetry is abnormal, as the separation of $1.5 \mathrm{~cm}$ greater than the contralateral side in any position recommended scapular dyskinesia [6].

The measurements obtained with the LSST are considered reliable and valid as the Kibler's test interrater reliability is moderate to fair for physical therapists and physicians in assessing scapular positioning or asymmetry (dyskinesia) [6].

\section{Measurement of scapular balance angle (SBA)}

The scapular position was determined through the measurement of SBA. The patient's position was remaining with his arms holding at both the side of the pelvis, the scapula inferior angle on the two sides was checked, and a line was drawn interfacing these marks. Another vertical line was drawn somewhere in the range of cervical (C7) and thoracic (T10) spinous process. The angles formed by the line interfacing both inferior angles of the scapula with the vertical line going through the spine [14].

The absolute difference between these two angles referred to the SBA [14]. In normal non-affected subjects, the values for the SBA were $2.505 \pm 2.340^{\circ}$ while the abnormal results were with an angle greater than $7.185^{\circ}$. An intraobserver intraclass correlation coefficient (ICC) of 0.87 and interobserver ICC of 0.84 was reported. SBA manual measurement is viewed as a straightforward and reproducible evaluation of the position of the scapula in clinical practice [14].

\section{Evaluation of upper extremity sensorimotor functions}

Fugl-Meyer Assessment upper extremity (FMAUE) scale used to evaluate the sensorimotor capacity of the upper extremity. FMAUE is viewed as valid and reliable for the evaluation of stroke patients [19]. The intra-rater reliability was high for the motor and sensory scores (0.951.0) [20]. The motor scores of the upper extremity going from 0 points (no active motion) to 66 (full active movement) and the score of the exteroceptive and proprioceptive sensations range from 0 to 12 . The most reduced and most noteworthy scores present the more terrible and better capacity separately. Every item of the FMAUE incorporated 3 points for every test, a zero score was given if the patient did not apply the assignment, and a score of 1 was given if the task performed was incomplete and a score of 2 for the complete execution of the task; however, the reflex was estimated utilizing just 2 points, with a score of 0 nonappearances or 2 for the presence of reflex.

The equipment \& tools needed for FMAUE were as follows: a seat, table, bed, stopwatch, and hammer for reflex assessment, ball of cotton, pencil, paper, little can, tennis ball, and a blindfold. The motor assessment included reflex action, flexor and extensor synergies of the upper extremity, movement combining synergies, development out of synergies, wrist strength, and coordination/ speed as a finger to nose test. The sensory assessment procedures included light touch and proprioception sensation with open then closed eyes for (shoulder, elbow, wrist, and thumb).

FMAUE motor scale scores classified as "no to poor" upper extremity capacity was < 31, while "limited capacity" represented 32 to 47 , "notable capacity" was 48 to 52 , and "full" upper extremity capacity was 53 to 66 [21].

\section{Data analysis}

General characteristics for the patients were compared between both groups using a $t$ test. Comparison of sex, type of stroke, recovery stages, affected side, and spasticity grade distribution between groups was carried out using the chi-squared test. The unpaired $t$ test was used for comparison of LSST, SBA, and FMAUE between both groups, $p<0.05$ represented the significance level. All statistical analysis was led through the statistical package for social studies (SPSS) version 25 for windows (IBM SPSS, Chicago, IL, USA).

\section{Results}

\section{Patient's characteristics}

The mean \pm SD of patients' characteristics and duration of illness of groups A and B demonstrated in Table 1.

Table 1 Basic characteristics of all participants

\begin{tabular}{|c|c|c|c|}
\hline & Group A & Group B & $\boldsymbol{p}$ value \\
\hline & $\bar{X} \pm S D$ & $\bar{X} \pm S D$ & \\
\hline Age (years) & $53.23 \pm 5$ & $54.43 \pm 5.6$ & 0.38 \\
\hline BMI $\left(\mathrm{kg} / \mathrm{m}^{2}\right)$ & $26.2 \pm 3.06$ & $25.46 \pm 3.05$ & 0.35 \\
\hline Duration of illness (months) & $7.3 \pm 1.31$ & $7.53 \pm 1.38$ & 0.5 \\
\hline \multicolumn{4}{|l|}{ Sex } \\
\hline Male & $12(52 \%)$ & $14(40 \%)$ & 0.39 \\
\hline Female & $18(48 \%)$ & $16(60 \%)$ & \\
\hline \multicolumn{4}{|l|}{ Types of stroke } \\
\hline Ischemic & $14(47 \%)$ & $18(60 \%)$ & 0.3 \\
\hline Hemorrhagic & $16(53 \%)$ & $12(40 \%)$ & \\
\hline \multicolumn{4}{|l|}{ Affected side } \\
\hline Right & $13(43 \%)$ & $14(47 \%)$ & 0.79 \\
\hline Left & $17(57 \%)$ & $16(53 \%)$ & \\
\hline \multicolumn{4}{|l|}{ Spasticity } \\
\hline Grade I & $1(3 \%)$ & $2(7 \%)$ & 0.6 \\
\hline Grade I $^{+}$ & $6(20 \%)$ & $8(27 \%)$ & \\
\hline Grade II & $15(50 \%)$ & $10(33 \%)$ & \\
\hline Grade III & $8(27 \%)$ & $10(33 \%)$ & \\
\hline \multicolumn{4}{|l|}{ Recovery stage "Brunnstrom" } \\
\hline Stage III & $23(77 \%)$ & $20(67 \%)$ & 0.39 \\
\hline Stage IV & $7(23 \%)$ & $10(33 \%)$ & \\
\hline
\end{tabular}

$\bar{x}$ mean, $S D$ standard deviation, $p$ value level of significance 
The results showed that between both groups, there was no significant difference in the mean age, BMI, and duration of illness $(p>0.05)$. Also, there was no significant difference in the distribution of sex, type of stroke, affected side, spasticity grades, and recovery stages between both groups $(p>0.05)$.

\section{LSST for scapular dyskinesia}

There was a significant increase in LSST of group A at 0,45 , and $90^{\circ}$ shoulder positions compared with that of group B $(p=0.001)$ (Table 2$)$.

\section{Effect of scapular dyskinesia on SBA and FMA-UE}

There was a significant increase in SBA of group A compared with that of group B $(p=0.001)$. There was a significant decrease in motor and sensory FMA-UE scores of group A compared with that of group B $(p=0.001)$ (Table 3).

\section{Discussion}

The results of the present study indicated that the hemiparetic upper extremity for group A with scapular dyskinesia showed a significant decrease in motor and sensory FMA-UE scores and a significant increase in SBA compared with that of the group B with no scapular dyskinesia. These findings outlined the significant effect of scapular dyskinesia on scapular position and sensorimotor function of the upper extremity. The asymmetry of scapular position is principal because of it changes the capacity of the muscles that control the scapula.

The scapula acts as a steady base for the motion of the arm. During arm movement, the muscles show a feedforward or expectant control action to guarantee that the scapular position is adjusted to the position of the humerus [22]. A sufficient positioning of the scapula is needed for the productivity of the powerful movement of the shoulder [23]. During motor functional tasks of the upper extremity the patients with stroke had a decreased capacity to perform isolated and particular arm motions due to the awkward nature of scapulohumeral muscles and scapulothoracic coordination [11]. Defect in the scapular posture cause changes in the length and

Table 2 Comparison of LSST between groups A and B

\begin{tabular}{ccllll}
\hline & Group A & Group B & MD $(95 \% \mathrm{Cl})$ & $\boldsymbol{T}$ value & $\boldsymbol{p}$ value \\
& $\overline{\mathrm{X}} \pm \mathrm{SD}$ & $\overline{\mathrm{X}} \pm \mathrm{SD}$ & & & \\
\hline LSST (cm) & & & & \\
$\mathbf{0}^{\circ}$ & $1.81 \pm 0.2$ & $0.9 \pm 0.29$ & $0.91(0.78-1.03)$ & 14.13 & $0.001^{\mathrm{a}}$ \\
$\mathbf{4 5}^{\circ}$ & $2.15 \pm 0.33$ & $1 \pm 0.3$ & $1.15(0.98-1.3)$ & 14.22 & $0.001^{\mathrm{a}}$ \\
$\mathbf{9 0}^{\circ}$ & $2.45 \pm 0.3$ & $1.21 \pm 0.21$ & $1.24(1.1-1.36)$ & 18.62 & $0.001^{\mathrm{a}}$ \\
\hline
\end{tabular}

LSST lateral scapular slide test, $\bar{x}$ mean, $S D$ standard deviation, MD mean difference, $\mathrm{Cl}$ confidence interval $p$ value level of significance, ${ }^{\mathrm{a}}$ Significant muscle strength of the shoulder region that alters the mechanics of the glenohumeral joint [24].

The absence of retraction presented with the scapular dyskinesia causes loss of balance with arm elevation, and the lack of scapular protraction around the chest increases the deceleration of the powers at the shoulder joint and changes in the glenoid and the humerus connection [25]. In stroke patients, the scapular asymmetry is due to winging as well as tipping (scapula makes tracks in an opposite direction from the thorax because of the absence of scapular steadiness by the serratus anterior), this happens principally because of gravitational powers [26]. There is a decrease of subacromial space in scapular dyskinesis [27] and a decline in rotator cuff power [28]. Rotator cuff weakness may debilitate motor control and greater mechanical damage of the subacromial space structures [29].

The result of this study is in agreement with the findings of Hou [30] who supported that spastic scapular dyskinesia leads to impaired shoulder active and passive ROM after stroke. A study by Dabholkar et al. [31] also supported and agreed with the present study results as it investigated the scapular dyskinesia on 50 stroke patients and the results showed that the scapular dyskinesia was evident in $64 \%$ of patients, and the SBA was $\leq 4$ in $24 \%$ of patients, 5 to $7^{\circ}$ in $50 \%$ of patients, and $>7^{\circ}$ in $26 \%$ of patients, while the stroke disability assessment scale showed 19 patients with mild disability, 24 with moderate disability, and 7 patients with severe disabilities. Scapular poor steadiness, position, and arrangement, on the chest affect the accessible scope of movement of the shoulder which may subsequently block function utilization of the upper limb.

Scalha et al. [32] demonstrated a direct connection between the FMA and with light touch exteroceptive sensation in the arm, elbow, and hand with Nottingham Tactile Appraisal. De Baets et al. [11] recommended that due to loss of particular muscle activation after the stroke that leads to changes in the scapular and glenohumeral stabilizers, the synchronized activation of shoulder force couple is very important for motor control of the shoulder, framed by the upper trapezius, lower trapezius, and serratus foremost to upward pivot the scapula [22].

Joshi and Naik [33] reported that in stroke patients, the scapula was pulled in descending revolution by gravity. The patients' posture of forward trunk flexion permits scapula elevation on the thorax and fortifies scapular descending pivot. The direction of the glenoid fossa changes with the goal that it was confronting descending as opposed to face upward, forward, and outward. This changed position of scapula influences the glenohumeral scope of movement and motor elements of the upper limb in stroke patients. 
Table 3 Comparison of SBA and FMAUE between groups A and B

\begin{tabular}{|c|c|c|c|c|c|}
\hline & \multirow{2}{*}{$\begin{array}{l}\text { Group A } \\
\bar{x} \pm S D\end{array}$} & Group B & \multirow[t]{2}{*}{ MD $(95 \% \mathrm{Cl})$} & \multirow[t]{2}{*}{$\boldsymbol{T}$ value } & \multirow[t]{2}{*}{$\boldsymbol{p}$ value } \\
\hline & & $\bar{x} \pm S D$ & & & \\
\hline SBA (degrees) & $9.43 \pm 1.86$ & $4.03 \pm 1.37$ & $5.4(4.55-6.24)$ & 12.73 & $0.001^{a}$ \\
\hline \multicolumn{6}{|l|}{ FMAUE } \\
\hline Motor & $35.23 \pm 3.61$ & $48.86 \pm 7.01$ & $-13.63(-16.51--10.57)$ & -9.46 & $0.001^{\mathrm{a}}$ \\
\hline Sensory & $7.1 \pm 1.4$ & $9.1 \pm 1.24$ & $-2(-2.68--1.31)$ & -5.85 & $0.001^{a}$ \\
\hline
\end{tabular}

SBA scapular balance angle, FMAUE Fugl-Meyer assessment upper extremity, $\overline{\mathrm{X}}$ mean, $S D$ standard deviation, $M D$ mean difference, $C I$ confidence interval $p$ value level of significance, ${ }^{\text {aSignificant }}$

Kibler et al. [6] stated that the scapular muscle fatigue and scapular muscle imbalance or weakness may lead to changes of glenohumeral proprioception (deep sensation), muscular inhibition, impaired coordination, and timing of movements are considered causes for scapular dyskinesia. Also, the proprioceptive dysfunction and injury to the joint can alter sensory information provided by mechanoreceptors which can lead to scapular dyskinesia.

The sensorimotor framework is characterized as the combination of tactile and motor systems that required in keeping up joint steadiness. The proprioception is responsible for arranging and adjustment of motor directions and changing places of the joints required to represent the complex mechanical cooperation inside the musculoskeletal framework [34]. The findings of the examination by Turgut and Baltaci [35] indicated that the dynamic developments of the scapula required control of the neuromuscular system and sensorimotor framework combination for the capacity to effectively put the hand and upper limb in the space.

DePalma and Johnson [36] noticed that scapular poor balance, position, and arrangement on the chest would influence fundamentally the shoulder scope of movement and subsequently decline the upper extremity functional activity. Park et al. [37] expressed that the scapula influences the shoulder joint and has a significant contribution to altering its position. Additionally, a report by Park et al. [37] endorsed that reinforcing the scapular stabilizer muscles could avoid scapula dyskinesis which thusly improves the capacity in the upper limb in stroke patients. Likewise, Park et al. [37] and Hardwick and Lang [9] affirmed the significance of the management of scapular position alternation to improve the upper extremity capacity of stroke patients.

Sanjukta et al. [38] stated that scapular dyskinesis produces abnormal synergistic movements of the scapula during arm raising activity and prevents the upper limb normal motor functioning of the affected side and restricts the scapular normal movements [39]. Some variables could influence the strength of the limb, for example, feedback loops including mechanoreceptors of joint and musculotendinous that are coordinated by the neurological system, and the proprioceptive loops, which is viewed as the particular variety of sensory methodology of touch and envelops the joint movement (kinesthesia) sensation and joint position sense [40].

Scapular dyskinesia may bring about the incredible impact on sensorimotor, tactile capacities, and daily functions, likewise influencing the joint position sense because of disturbance of ordinary neuromuscular reflex joint adjustment, as any adjustments in the articular mechanoreceptors would bring out sensory inputs that decrease the sensitivity of muscle spindle and hence diminishing proprioception, which show that the role of the proprioceptive system in keeping the shoulder balance and functional activities [41].

The results of the present study explained the impact of scapular dyskinesia on upper-limb sensorimotor function and scapular position. This study provides quantitative measurements of both variables. Most of the previous studies concentrate on the effect of scapular dyskinesia on motor function while this study includes the assessment of the sensory domain also. The finding of this study may direct the attention of the clinician to attempt to prevent the development of scapular dyskinesia in patients with hemiplegia and highlights the importance of early rehabilitation of scapular muscles as a base to restore the upper extremity functions.

There are some limitation in this study, as the electromyography (EMG) studies of scapular muscles were not included in the investigation. X-ray for glen-humeral joint and scapulothoracic joint articulation was not included in the assessment of scapular alignments. For future studies, it would be beneficial to include these assessment methods in the investigation of the effect of scapular dyskinesia on the spine or other neurological conditions.

\section{Conclusion}

Based on the findings of this study, we can conclude that a high score of scapular dyskinesia had a great effect on the scapular balance angle and upper extremity sensorimotor function in a spastic stroke patient. So that the scapular dyskinesia management should be considered in the rehabilitation program for stroke patients with spasticity. 


\section{Abbreviations}

EMG: Electromyography; FMA: Fugl-Meyer Assessment; FMAUE: Fugl-Meyer Assessment upper extremity; ICC: Correlation coefficient; LSST: Lateral scapular slide test; PALM: Palpation meter; SBA: Scapular balance angle

\section{Acknowledgements}

The authors acknowledge the patients for their participation and cooperation in the study.

\section{Authors' contributions}

LS and SM collected all the measurements data. SM analyzed and interpreted the patient data regarding the disease. LS was a major contributor in writing the manuscript. The authors read and approved the final manuscript.

\section{Funding}

This research did not receive any specific grant from funding agencies in the public, commercial, or not-for-profit sectors.

\section{Availability of data and materials}

The datasets generated and/or analyzed during the current study are not publicly available due to current Cairo University regulations and Egyptian legislation but are available from the corresponding author on reasonable request and after institutional approval.

\section{Ethics approval and consent to participate}

All the patients received verbal and written information about the study and gave written consent to participate, before the beginning of the study. The anonymity and confidentiality were assured, and all the procedures were performed in compliance with relevant laws and institutional guidelines. The study was approved by the Institutional Ethics Committee of the Faculty of Physical Therapy, Cairo University, Egypt (No: P.T.REC/012/002400) and followed the Helsinki Declaration of 1975, as revised in 2000 for procedures involving human participants, and with a ClinicalTrials.gov ID NCT04004949.

\section{Consent for publication}

All the patients received verbal and written information about the study and gave written consent to participate, before the beginning of the study. The anonymity and confidentiality were assured, and all the procedures were performed in compliance with relevant laws and institutional guidelines.

\section{Competing interests}

The authors declare that they have no competing interests.

\section{Author details}

${ }^{1}$ Department of Neuromuscular Disorders and Its Surgery, Faculty of Physical Therapy, October 6 University, Giza, Egypt. ²Department of Biomechanics, Faculty of Physical Therapy, Cairo University, Cairo, Egypt.

Received: 24 April 2020 Accepted: 3 June 2020

Published online: 09 July 2020

\section{References}

1. Shim S, Kim H, Jung J. Comparison of upper extremity motor recovery of stroke patients with actual physical activity in their daily lives measured with accelerometers. J Phys Ther Sci. 2014;26:1009-11. https://doi.org/10. 1589/jpts.26.1009.

2. Brown A. J. Chapter 15. Recovery of motor function after stroke. Prog Brain Res. 2006;157:223-8. https://doi.org/10.1016/S0079-6123(06)57015-3.

3. Cailliet A. Shoulder Pain. PA, FA Davis Co 1966:33-58.

4. Murie-Fernández M, Iragui MC, Gnanakumar V, Meyer M, Foley N, Teasell R Painful hemiplegic shoulder in stroke patients: causes and management. Neurología (English Edition), 2012;27:234-44. doi: https://doi.org/10.1016/j. nrl.2011.02.010.

5. Hefter H, Jost WH, Reissig A, Zakine B, Bakheit AM, Wissel J. Classification of posture in poststroke upper limb spasticity: a potential decision tool for botulinum toxin a treatment? Int J Rehabil Res. 2012;35:227-33. https://doi. org/10.1097/MRR.0b013e328353e3d4.

6. Kibler WB, Ludewig PM, PW MC, Michener LA, Bak K, Sciascia AD. Clinical implications of scapular dyskinesis in shoulder injury: the 2013 consensus statement from the scapular summit. Br J Sport Med. 2013;47:877-85. https://doi.org/10.1136/bjsports-2013-092425.

7. Kibler WB, Ludewig PM, MPW. Scapula summit 2009. J Orthop Sport Phys Ther. 2009:39:A1-13. https://doi.org/10.2519/jospt.2009.0303.

8. Barnes CJ, Van Steyn SJ, Fischer RA. The effects of age, sex, and shoulder dominance on range of motion of the shoulder. J Shoulder Elb Surg. 2001; 10:242-6. https://doi.org/10.1067/mse.2001.115270.

9. Hardwick DD, Lang CE. Scapular and humeral movement patterns of people with stroke during range of motion exercises. J Neurol Phys Ther JNPT. 2011;35:18. https://doi.org/10.1097/NPT.0b013e318208efa1.

10. Ludewig PM, Cook TM. Alterations in shoulder kinematics and associated muscle activity in people with symptoms of shoulder impingement. Phys Ther. 2000;80:276-91. https://doi.org/10.1093/ptj/80.3.276.

11. De Baets $L$, Jaspers $E$, Janssens $L$, Van Deun S. Characteristics of neuromuscular control of the scapula after stroke: a first exploration. Front Hum Neurosci. 2014;8:933. https://doi.org/10.3389/fnhum.2014.00933.

12. Martin RM, Fish DE. Scapular winging: anatomical review, diagnosis, and treatments. Curr Rev Musculoskelet Med. 2008;1:1-11. https://doi.org/10. 1007/s12178-007-9000-5.

13. Sciascia A, Cromwell R. Kinetic chain rehabilitation: a theoretical framework. Rehabil Res Pract. 2012;2012. https://doi.org/10.1155/2012/853037.

14. Contreras J, Gil D, de Dios Errázuriz J, Ruiz P, Diaz C, Águila P. Scapular balance angle reference values in a healthy population. Revista Española de Cirugía Ortopédica y Traumatología (English Edition), 2014;58:24-30. doi: https://doi.org/10.1016/j.recot.2013.09.009.

15. Gladstone DJ, Danells CJ, Black SE. The Fugl-Meyer assessment of motor recovery after stroke: a critical review of its measurement properties. Neurorehabil Neural Repair. 2002;16:232-40. https://doi.org/10.1177/ 154596802401105171

16. Meseguer-Henarejos A-B, Sanchez-Meca J, Lopez-Pina J-A, Carles-Hernandez R. Inter-and intra-rater reliability of the modified Ashworth scale: a systematic review and meta-analysis. Eur J Phys Rehabil Med. 2018:54:57690. https://doi.org/10.23736/S1973-9087.17.04796-7.

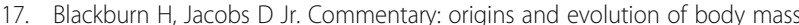
index (BMI): continuing saga. Int J Epidemiol. 2014;43:665-9. https://doi.org/ 10.1093/ije/dyu061.

18. Faul F, Erdfelder E, Buchner A, Lang A-G. Statistical power analyses using G* power 3.1: tests for correlation and regression analyses. Behav Res Methods. 2009;41:1149-60. https://doi.org/10.3758/BRM.41.4.1149.

19. Page SJ, Fulk GD, Boyne P. Clinically important differences for the upperextremity Fugl-Meyer scale in people with minimal to moderate impairment due to chronic stroke. Phys Ther. 2012;92:791-8. https://doi.org/10.2522/ptj.20110009.

20. Sullivan KJ, Tilson JK, Cen SY, Rose DK, Hershberg J, Correa A. Fugl-Meyer assessment of sensorimotor function after stroke: standardized training procedure for clinical practice and clinical trials. Stroke. 2011;42:427-32. https://doi.org/10.1161/STROKEAHA.110.592766.

21. Hoonhorst MH, Nijland $\mathrm{RH}$, van den Berg JS, Emmelot $\mathrm{CH}$, Kollen BJ, Kwakkel G. How do Fugl-Meyer arm motor scores relate to dexterity according to the action research arm test at 6 months poststroke? Arch Phys Med Rehabil. 2015 96:1845-9. https://doi.org/10.1016/j.apmr.2015.06.009.

22. Ebaugh DD, McClure PW, Karduna AR. Three-dimensional scapulothoracic motion during active and passive arm elevation. Clin Biomech. 2005;20:7009. https://doi.org/10.1016/j.clinbiomech.2005.03.008.

23. van Andel C, van Hutten K, Eversdijk M, Veeger D, Harlaar J. Recording scapular motion using an acromion marker cluster. Gait Posture. 2009;29: 123-8. https://doi.org/10.1016/j.gaitpost.2008.07.012.

24. Borloz S, Graf V, Gard S, Ziltener J-L. Scapular dyskinesis. Rev Med Suisse. 2012:8:2422-8

25. Sanchez H, de Morais Sanchez E. Scapular dyskinesis: biomechanics, evaluation and treatment. Int Phys Med Rehabil J. 2018;3. https://doi.org/10. 15406/ipmrj.2018.03.00157.

26. Oatis CA. Joint structure and function: a comprehensive analysis, ed 2. Norkin CC, Levangie PK. Philadelphia, PA, F a Davis co, 1992, hard cover, 512 pp, illus, \$34.95. J Phys Ther Educ. 1993;6:70. https://doi.org/10.1097/ 00001416-199207000-00024.

27. Silva RT, Hartmann LG, de Souza Laurino CF, Biló JPR. Clinical and ultrasonographic correlation between scapular dyskinesia and subacromia space measurement among junior elite tennis players. Br J Sports Med. 2010;44:407-10. https://doi.org/10.1136/bjsm.2008.046284.

28. Tate AR, Mcclure P, Kareha S, Irwin D. Effect of the scapula reposition test on shoulder impingement symptoms and elevation strength in overhead 
athletes. J Orthop Sport Phys Ther. 2008;38:4-11. https://doi.org/10.2519/ jospt.2008.2616.

29. Phadke V, Camargo PR, Ludewig PM. Scapular and rotator cuff muscle activity during arm elevation: a review of normal function and alterations with shoulder impingement. Brazilian J Phys Ther. 2009;13:1-9. https://doi. org/10.1590/S1413-35552009005000012.

30. Hou S, Ivanhoe C, Li S. Botulinum toxin injection for spastic scapular dyskinesia after stroke: case series. Medicine (Baltimore). 2015;94. https://doi. org/10.1097/MD.0000000000001300

31. Dabholkar A, Mehta D, Yardi S, Dabholkar T. Assessment of scapular behaviour in stroke patients. Int J Heal Rehabil Sci. 2015;4:95-102. https:// doi.org/10.5455/ijhrs.000000079.

32. Scalha TB, Miyasaki E, Lima NMFV, Borges G. Correlations between motor and sensory functions in upper limb chronic hemiparetics after stroke. Ara Neuropsiquiatr. 2011:69:624-9. https://doi.org/10.1590/50004282X2011000500010

33. Joshi S, Naik D. Effect of scapular malpositioning on shoulder range of motion in stroke patients. Int J Curr Res Rev. 2016;8:17.

34. Riemann BL, Lephart SM. The sensorimotor system, part II: the role of proprioception in motor control and functional joint stability. J Athl Train. 2002;37:80.

35. Turgut E, Baltaci G. Effect of flexibility deficit on scapular asymmetry in individuals with and without shoulder pain. Brazilian J Phys Ther. 2018;22: 370-5. https://doi.org/10.1016/j.bjpt.2018.03.007.

36. DePalma MJ, Johnson EW. Detecting and treating shoulder impingement syndrome: the role of scapulothoracic dyskinesis. Phys Sportsmed. 2003;31: 25-32. https://doi.org/10.3810/psm.2003.07.431.

37. Park S-E, Kim Y-R, Kim Y-Y. Immediate effects of scapular stabilizing exercise in chronic stroke patient with winging and elevated scapula: a case study. J Phys Ther Sci. 2018;30:190-3. https://doi.org/10.1589/jpts.30.190.

38. Sanjukta S, Sayli P,Snehal G. To study the effect of kinesiotaping on scapular stability and upper limb function in sub-acute and chronic stroke patients. A pilot study (case series). Int J Allied Med Sci Clin Res. 2017;5:443-9.

39. Shah $D$, Balusamy $D$, Verma $M$, Jui $G$, et al. Comparative study of the effect of taping on scapular stability and upper limb function in recovering hemiplegics with scapular weakness. Chronicles Young Sci. 2013;4:121. https://doi.org/10.4103/2229-5186.115551.

40. Schulte RA, Warner C. Oscillatory devices accelerate proprioception training. Clin Biomech. 2001;6:85-91.

41. Ishita S, Siddhartha S, Umer A. Effect of electrical muscle stimulation with voluntary contraction and taping on joint position sense in asymptomatic scapular dyskinesic patients. Int J Phys Med Rehabil. 2014;2:2. https://doi. org/10.4172/2329-9096.1000190.

\section{Publisher's Note}

Springer Nature remains neutral with regard to jurisdictional claims in published maps and institutional affiliations.

\section{Submit your manuscript to a SpringerOpen ${ }^{\circ}$ journal and benefit from:}

- Convenient online submission

- Rigorous peer review

- Open access: articles freely available online

- High visibility within the field

- Retaining the copyright to your article

Submit your next manuscript at $\boldsymbol{\nabla}$ springeropen.com 